Journal of Advanced Research in Fluid Mechanics and Thermal Sciences

Journal homepage: www.akademiabaru.com/arfmts.html ISSN: $2289-7879$

\title{
Numerical Analysis of Flow and Heat Transfer Enhancement in A Horizontal Pipe with Plain and Dimple Twisted Tape
}

\author{
Harish H. V. ${ }^{1}$, Manjunath K. ${ }^{1}{ }^{*}$, Rangaswamy T. ${ }^{2}$ \\ Department of Mechanical Engineering, Government Engineering College, Hassan, India \\ Department of Mechanical Engineering, Government Engineering College, Mosale Hosahalli, Hassan District, India
}

\section{ARTICLE INFO}

Article history:

Received 25 January 2021

Received in revised form 24 March 2021

Accepted 28 March 2021

Available online 9 May 2021

Keywords:

Convection heat transfer; Friction factor; Hemispherical twisted tape; Laminar flow; Thermo-hydraulic

\section{ABSTRACT}

In order to improve thermo-hydraulic performance of laminar flow various techniques has been used among which a plain tube with twisted tape insert is widely used. The main objective is to numerically study flow field in order to enhance heat transfer, through a circular pipe built in with/without Dimples on twisted strip. Effect of plain and dimple strip on thermo hydraulic performance discussed. The analysis results for laminar range of $800 \leq \operatorname{Re} \leq 2000$ is obtained with twist ratio of the strip is 3.0. Analysis is carried for full length tape with constant heat flux. The simulation results of Nusselt number versus Reynolds number of the plain, plain twisted tape and Dimple twisted tape with the experimental data give variation of 2.5, 5.75 and 9.5\%. The friction factor of Dimple twisted tape tube is 6 to 13 times that of the plain tube. The thermal performance factor of the Dimple twisted tape and plain twisted tape tube is 4 to $15 \%$ and 3 to $12 \%$ respectively higher than that of plain tube. Due to increase in thermal performance factor of induced strip with dimples there is an intensification of heat transfer obtained through circular duct with dimple twisted tape insert than that of plain twisted tape and plain pipe. The use of a twisted tube compounded with dimples is feasible in terms of energy saving at lower Reynolds numbers. Present study is applicable for design of compact heat exchanger in order to optimize energy consumption.

\section{Introduction}

Heat transfer intensification gives energy saving, heat exchangers are commonly used in many industries such as the chemical industry, cooling and air conditioning, power generation, etc. The optimal heat exchanger design is to decrease flow resistance while increasing the coefficient of heat transfer. In order to increase temperature uniformity and reduce flow resistance, the idea of heat transfer improvement in the core flow of the tube is proposed.

How to increase thermal output factor with centre cleared twisted tape, heat transfer and friction factor properties of laminar flow have been numerically studied by Guo et al., [1].

\footnotetext{
* Corresponding author.

E-mail address: harris.mech94@gmail.com
}

https://doi.org/10.37934/arfmts.82.2.106119 
Wongcharee and Eiamsa-ard [2] performed experiments on laminar flow by inserting strips through a circular pipe and found an increase in energy transfer compared to that of plain tube.

Eleiwi et al., [3] numerically studied Fluid Flow and Heat Transfer in a Backward Facing Step with Three Adiabatic Circular Cylinder and found the heat transfer enhancement increases from (6\%) to (13\%) if the Reynolds number change from (50) to (250) when heat flux increases (67\%).

Yang and Liu [4[ and Liu and Yang [5] proposed by strengthening temperature uniformity, increasing flow disturbance in the core flow, reducing surface area in the core flow and decreasing fluid disturbance in boundary flow an efficiency of core flow will increase. An experimental study in which swirl has been implemented by inserting twisted tape [6], short length twisted tape inserts Have a higher rate of energy transfer than plain tubes. Promvonge and Eiamsa-ard [7] performed experimental studies and found that a lower twist ratio would have a greater energy transfer and friction factor for all Re numbers.

Piya et al., [8] carried out numerical simulation in order to study heat transfer characteristic of inclined oval trench and found that area of high Nusselt number corresponded to the area of high total pressure coefficient. When inclined angle became larger, the areas of Nusselt number and high total pressure coefficient took place at dimple edge in $+Z$ direction.

Sarviya and Fuskele [9] investigated experimentally by inserting twisted tape with rectangular cut edges. Found a rise in the rate of energy transfer and friction factor. Research work on energy transfer was carried out by Kumar et al., [10]; friction factor by supplying a multi V-shaped rib through a solar heater duct; and maximum values of energy transfer and friction factor were observed.

Kongkaitpaiboon et al., [11] conducted his research on the characteristics of energy transfer and Friction factor by inserting conical and perforated conical rings and found that PCR provides low energy transfer enhancement compared to Khoshvaght-Aliabadi and Arani-Lahtari [12] numerically studied twisted mini channel forced convection and analyzed working fluid effect and twist pitch. The thermo-hydraulic output of laminar flow through a pipe with helical screw tape and wire coil inserts was evaluated by Roy and Saha [13].

Arulprakasajothi et al., [14] investigated the effect of staggered and non-staggered conical strip inserts in a circular tube under laminar flow condition. The conical strip of forward and backward direction was used as turbulators which led to enhanced heat transfer coefficient Smith Eiamsa-ard et al., [15] performed experiments for peripherally cut twisted tape with constant twist ratio of 3. Experiments were performed for different tape width and depth ratios in the range of Re 100020,000 . They concluded that the peripherally cut twisted tape had better performance compared to a plain tube. TPF achieved was 2.28-4.88 in laminar regime and 0.88-1.29 in turbulent regime.

Numerical study of heat transfer characteristics in laminar flow have been carried out by Lin et al., [16] using twisted tape having parallelogram winglet vortex generator. This newly designed twisted tape has two ways to generate secondary flow which includes secondary flow generated by base tape and secondary flow generated by the parallelogram winglet. They observed improvement in TPF ranges from 1.25 to 1.85 for the studied range of Re.

Feng et al., [17] to study the effect of wire coil inserts on laminar flow in rectangular microchannel heat sink using ANSYS CFX. From the results, they concluded that the wire coil insert performed best only in case of the low Re flow. Bhadouriya et al., [18] used the twisted square duct and the twisted elliptical pipe as a heat transfer enhancement technique. They investigated the heat transfer characteristics for the broad range of Re and Pr. Uniform wall temperature was considered as a boundary condition. Due to twist, swirl and secondary flow are produced at the corner which leads to enhancement in heat transfer coefficient. The results showed that the heat 
transfer rate and pressure drop increased considerably in laminar as well as turbulent flow for Re up to 9300.

A comparative investigation of enhanced heat transfer and friction factor by insertion of twisted tapes in a round tube is presented by Rahim-Esbo et al., [19]. Ranjan et al., [20] performed experiment in non-circular channels in the laminar regime. Heat transfer enhancement and increase in pressure drop occurred and heat transfer intensification dominated over the increase in pressure drop.

Abdullah and Yilmaz [21] performed Analysis of Heat Transfer Enhancement in a Circular Tube Fitted with Different Inserts and found that highest overall enhancement efficiency of $126 \%$ and $150 \%$ are achieved for the isosceles triangle wire coil with $a / D=0.4$ and twisted tape, respectively at $P / D=1$ and Reynolds number of 20000 . Finally an conclusion has been drawn from above analysis study that twisted tape has the ability to enhance the heat transfer with higher efficiency comparing to the wire coils isosceles triangle cross section and plane tube.

The present study involves intensifying heat transfer. The effect of dimples provided on full length tape on friction factor and Nusselt number studied. The numerical analysis is carried out for laminar range of $800 \leq \mathrm{Re} \leq 2000$ and under constant heat flux. Numerical analysis carried out for PT and TT tube is compared.

\section{Methodology}

\subsection{Numerical Method Description and Assumption of Model}

The geometry of flow domain is as shown in Figure 1; pipe length is $1000 \mathrm{~mm}$ with ID of $19 \mathrm{~mm}$ the thickness of strip is $1 \mathrm{~mm}$. The single twisted ratio of the strip is 3.0 and domain of full-length tape has been chosen. These dimensions were selected based on the experimental work of Wongcharee and Eiamsa-ard [2].

\subsection{Model Geometry}

The pipe geometry, shown in Figure 1, has dimension of length $1000 \mathrm{~mm}$, ID $19 \mathrm{~mm}$. Full length twisted tape has been selected for analysis which has thickness, pitch and width of 1, 54 and $18 \mathrm{~mm}$ as shown in Figure 2. These dimensions were selected based on the experimental work [2]. Further to enhance heat transfer dimples are provided on the strip which is as shown in Figure 3.

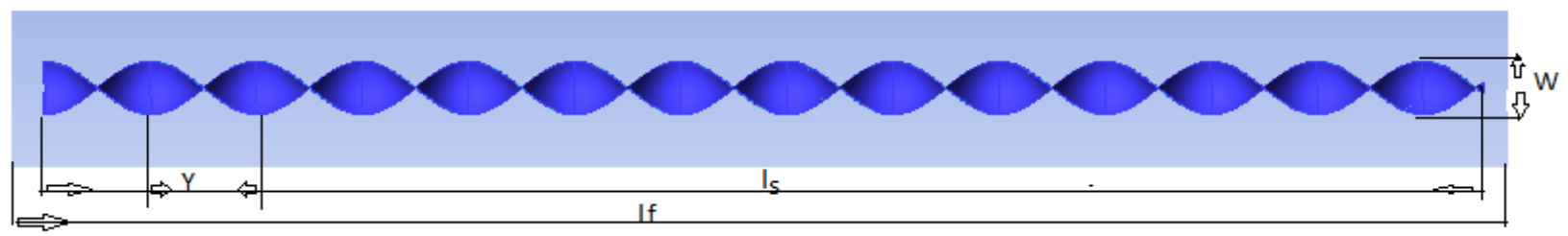

Fig. 1. Geometry of flow domain PTT

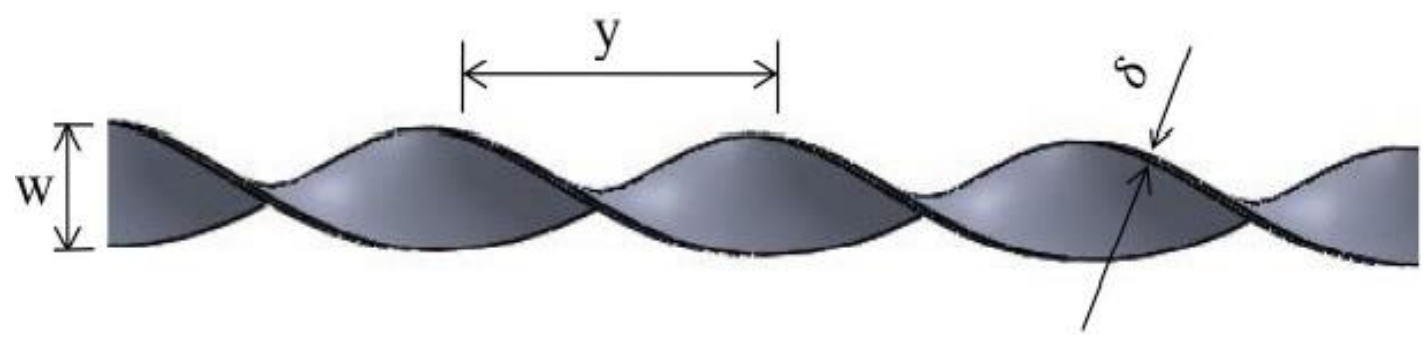

Fig. 2. Twisted tape TT 


$$
\begin{aligned}
& y / w=3.0 \\
& L R=1 \\
& D=19 \mathrm{~mm} \\
& W=18 \mathrm{~mm} \\
& y=54 \mathrm{~mm}
\end{aligned}
$$

The geometry of DTT is as shown in Figure 3.

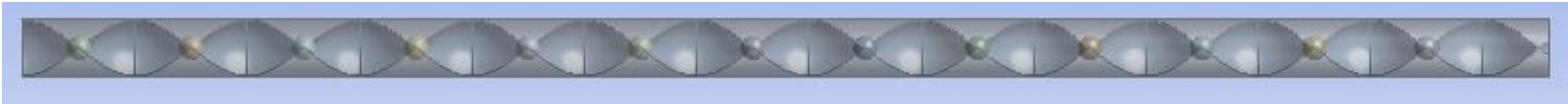

Fig. 3. Geometry of Dimple Twisted Tape

Diameter of Dimple $=10 \mathrm{~mm}$

Pitch of dimple $=y$

\subsection{Governing Equations and Boundary Conditions}

Continuity equation

$\nabla \cdot V=0$

Momentum equation

$\frac{\partial(\rho V)}{\partial t}+\nabla \cdot(\rho V V)=-\nabla p+\nabla \cdot \mu(\nabla V)$

Energy equation

$\rho C p\left(\frac{\partial T}{\partial t}+\nabla . V T\right)=\nabla \cdot(k . \nabla T)$

Each region of domain has been specified with has been specified with boundary conditions. Internal region has been specified as fluid domain.

Boundary condition for wall

$\mathrm{U}, \mathrm{V}=0,0$ and $\mathrm{q}=\mathrm{w}_{\text {all }}$

At the inlet of the pipe is

$\mathrm{U}=\mathrm{U}_{\text {in }}, \mathrm{V}=0, \mathrm{~T}=\mathrm{T}_{\mathrm{in}}$

Fully developed flow has been specified at out let with $\mathrm{P}=0$.

$\mathrm{Nu}=\mathrm{hD} / \mathrm{k}$

The non-dimension number $\operatorname{Re}=\rho U D / \mu$ 


\subsection{Grid Resolution}

In order to obtain high accuracy of numerical results grid independence test were conducted, four different grid were used for each domain as shown in table. Temperature at the exit of the domain has been choosen as variable for grid independence test for Reynolds number 1800. Results of temperature for grid resolution test of DTT as shown in Figure 4. For DTT, there is a variation of $5.1 \%, 3.9 \%$ and $2.7 \%$ in comparing the values of temperature obtained in the grids with the total number of cells 983074, 1215216 and 1538259 respectively with the grid with the number of cells 913694. The cells 1712570 gives variable output of temperature at outlet less than cells 1538259 . Hence cells 1538259 have been optimized for analysis. The PT (Table 1) indicates a variation of $4.1 \%, 3.6 \%$ and $2.9 \%$ in comparing the values of temperature in the grids the number of cells 469987,492346 and 526712 respectively with the grid with the number of cells 451186 . The cells 628347 gives variable output of temperature at outlet less than cells 526712 . Hence cells 526712 have been optimized for analysis.

Table 1

Grid resolution study

\begin{tabular}{|c|c|c|c|c|c|}
\hline Domain & Number & & & & \\
\hline PT & 451186 & 469987 & 492346 & 526712 & 628347 \\
\hline DTT & 913694 & 983074 & 1215216 & 1538259 & 1712570 \\
\hline
\end{tabular}

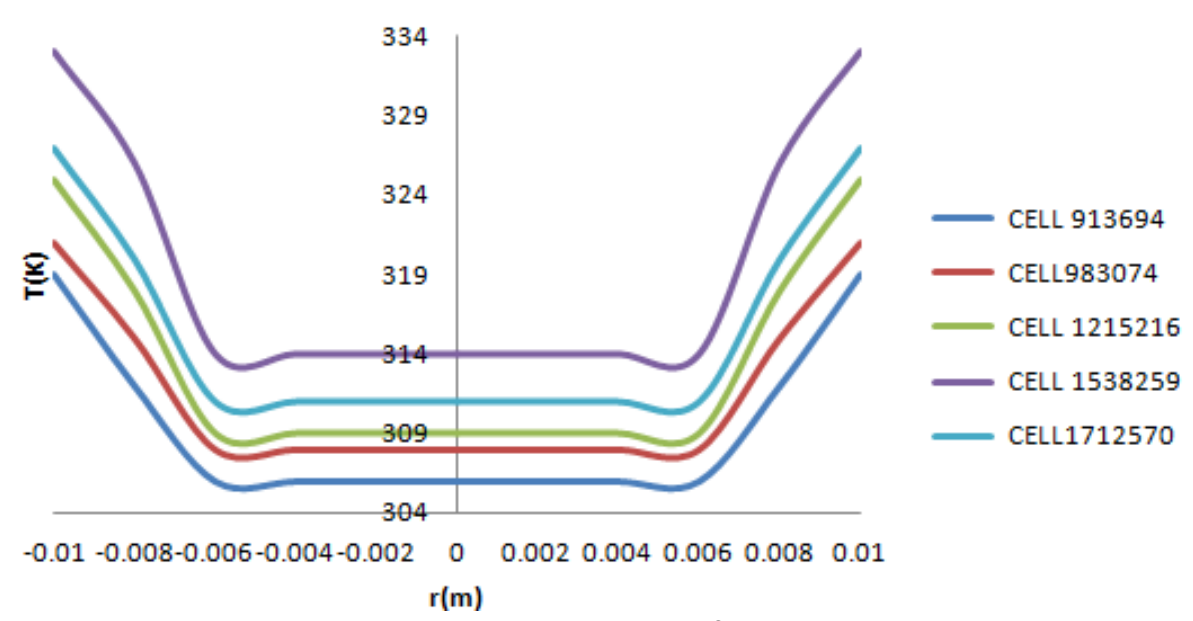

Fig. 4. Grid Resolution of DTT tube

\subsection{Heat Transfer Assessment}

For laminar flow the thermal transfer is presented by dimensionless quantity Nusselt number.

$\mathrm{Nu}=1 / \mathrm{L} \int_{0}^{L} \frac{D}{K} h(x) d x$

The heat transfer coefficient is given by

$h(x)=q^{\prime \prime} / T_{w}(x)-T_{m}(x)$

The term $T_{m}(x)$ is determined by

$T_{m}(x)=T_{m, i}+q " \pi D x / m c_{p}$ 


\section{Results and Discussion}

In this section, Nusselt number, friction factor, contour plots and thermal performance of the tubes are discussed. A Reynolds number $\operatorname{Re}=1800$ is selected to discuss contour profiles.

A result of $\mathrm{Nu}$ and friction factor $\mathrm{f}$, for PT tube is compared with experimental data of Wongcharee and Eiamsa-ard [2]. A result of Nu and friction factor $f$, for PTT and DTT is compared with experimental data of Wongcharee and Eiamsa- ard [2] and correlation of Hong and Bergles. Effect of PTT, DTT inserts on energy transfer and friction factor are reported in present section. The correlation of Hong and Bergles is given by

$N u=5.17\left[1+5.484 \times 10^{-3} \mathrm{pr}^{0.7}\left(\frac{R e}{y}\right)^{1.25}\right]^{0.5}$

The Nusselt number verses Re number of the plain tube (PT) with the experimental data, as shown in Figure 5 , which gives a variation of $2.5 \%$.

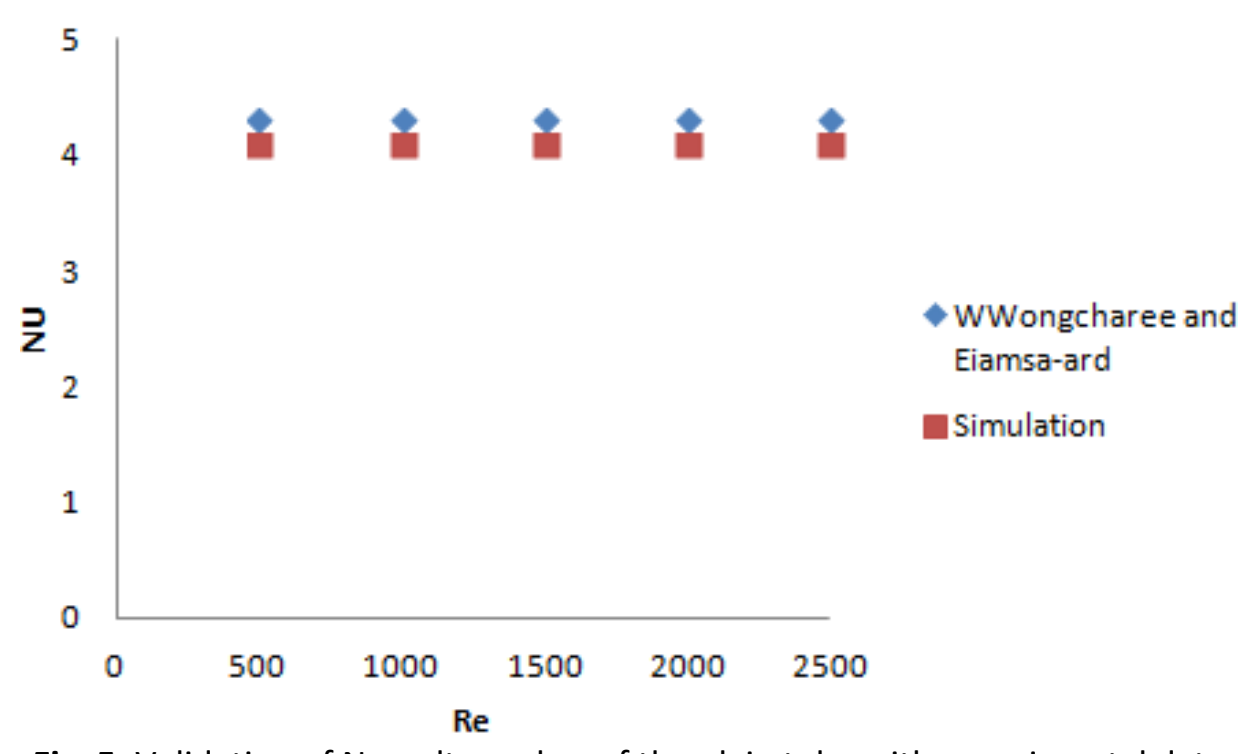

Fig. 5. Validation of Nusselt number of the plain tube with experimental data

\subsection{Effect of PTT and DTT}

Numerical investigation of forced convection over Reynolds number range of 800 to 2000 has been carried out. The variation of Nu with Re for PTT and DTT tube is compared with experimental data and found that maximum Nu and friction factor $(f)$ is obtained for DTT tube. Figure 6 shows the validation of the numerical result of PTT and DTT with the Wongcharee and Eiamsa-ard's [2] experiment and Hong and Bergles correlation. The numerical result of Nu number verses Reynolds number for PTT tube is in agreement with the experimental data with a deviation of $5.75 \%$ and when compared with a correlation of Hong and Bergles a deviation of $0.66 \%$ obtained which is outstanding. The numerical result of Nu number verses Reynolds number for DTT tube is in agreement with the experimental data with a deviation of 9.5\%. Its agreement with Hong and Bergles correlation is excellent with a deviation of $6.75 \%$. It should normally be remembered that as the Reynolds number rises, the Nusselt number rises. This is because of the friction that overcomes the fluid viscous power and decrease the shear between fluid and wall. 


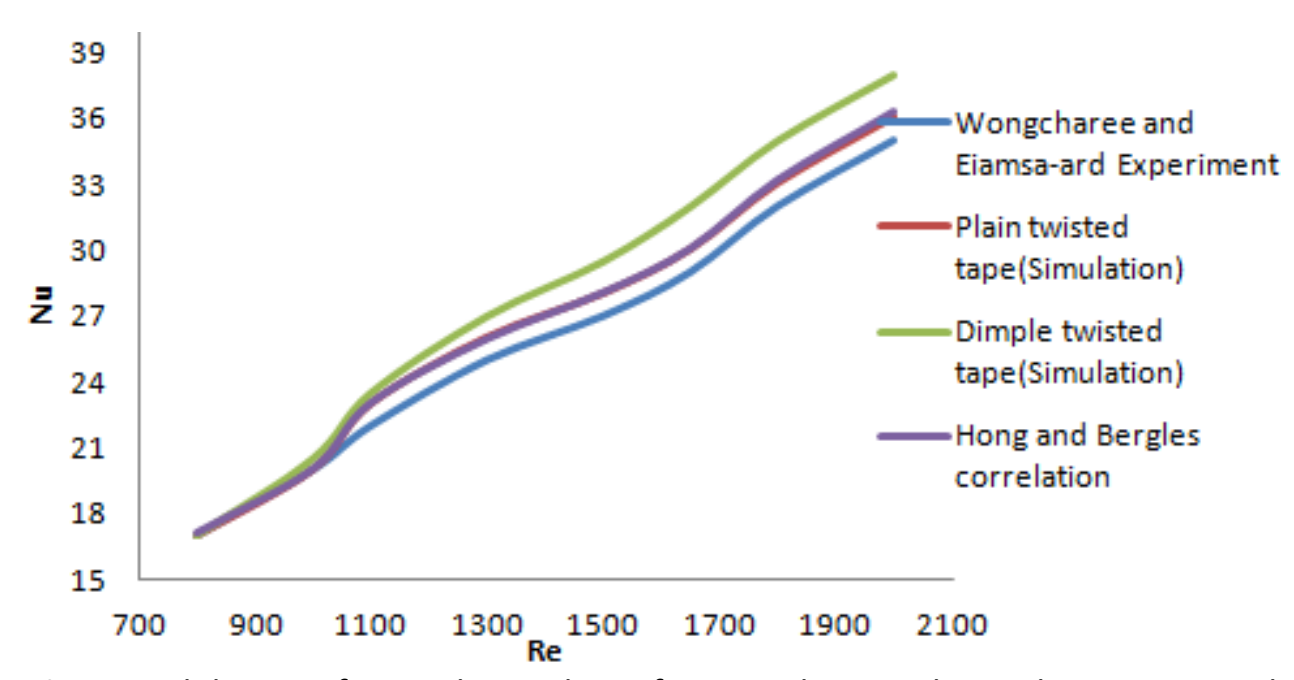

Fig. 6. Validation of Nusselt number of PTT and DTT tube with experimental data and correlation

\subsection{Effect of Friction Factor}

The decrease in pressure that occurs in the flow of a fluid is given by

$f=2 D \Delta P / U^{2} L \rho$

With the experimental results and the correlation of Donevski and Kuleszaard, the tube friction factor caused by plain twisted tape inserts (PTT) was validated. The correlation of Donevski and Kulesza is given as

$f=(15.625 / R e)\left[1+\left(0.85 / y^{2}\right)\right]^{1 / 2}\left[\frac{\pi+2-\delta}{\pi-4 \delta / D}\right]^{2}\left[\frac{\pi}{\pi-4 \delta / D}\right]$

The pressure drop that occurs in the flow of a fluid is the Darcy friction factor. With the experimental results (2), the plain tube friction factor was validated. The outcome reveals that there is a maximum difference of $1.5 \%$ between the friction factor for the simulated outcome and the experimental outcome. The friction factor of plain tube is validated with experimental results, shown in Figure 7.

The friction factor for the simulated outcome of PTT, DTT is validated with experimental results and correlation shown in Figure 8. For PTT there is a maximum difference of $4.5 \%$ with the experimental findings and the simulated outcomes agreed with the correlation of Donevski and kulesza with a 0.8 percent variance. For DTT there is a maximum difference of $6.5 \%$ with the experimental findings and the simulated outcomes agreed with the correlation of Donevski and kulesza with a $6.8 \%$ percent variance.

The above observations demonstrate that the simulated results are in very good agreement with the findings of experimentation and correlation. It is observed that when any of the twisted tape is inserted inside the tube, relative to the plain tube, the dropping trend of the friction factor becomes sharper. This is due to the blockage imparted on the flow by the tapes and thereby decreasing the flow momentum. 


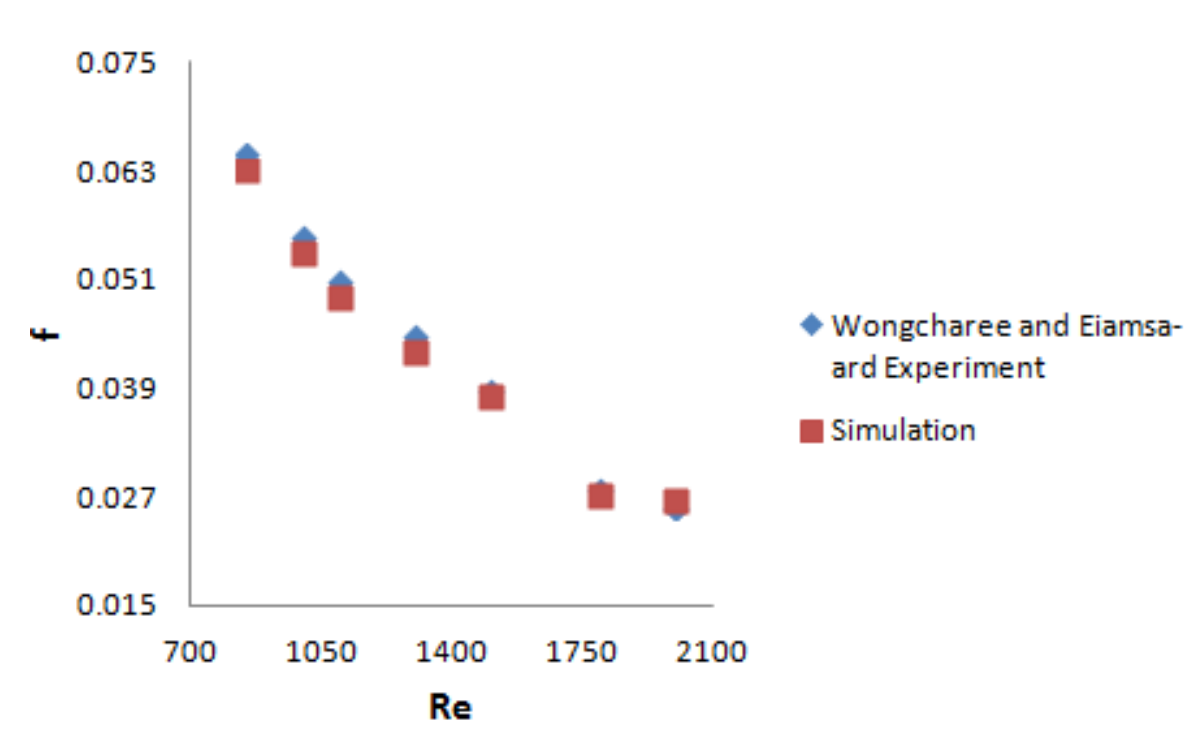

Fig. 7. Validation of friction factor of the plain tube with experimental data

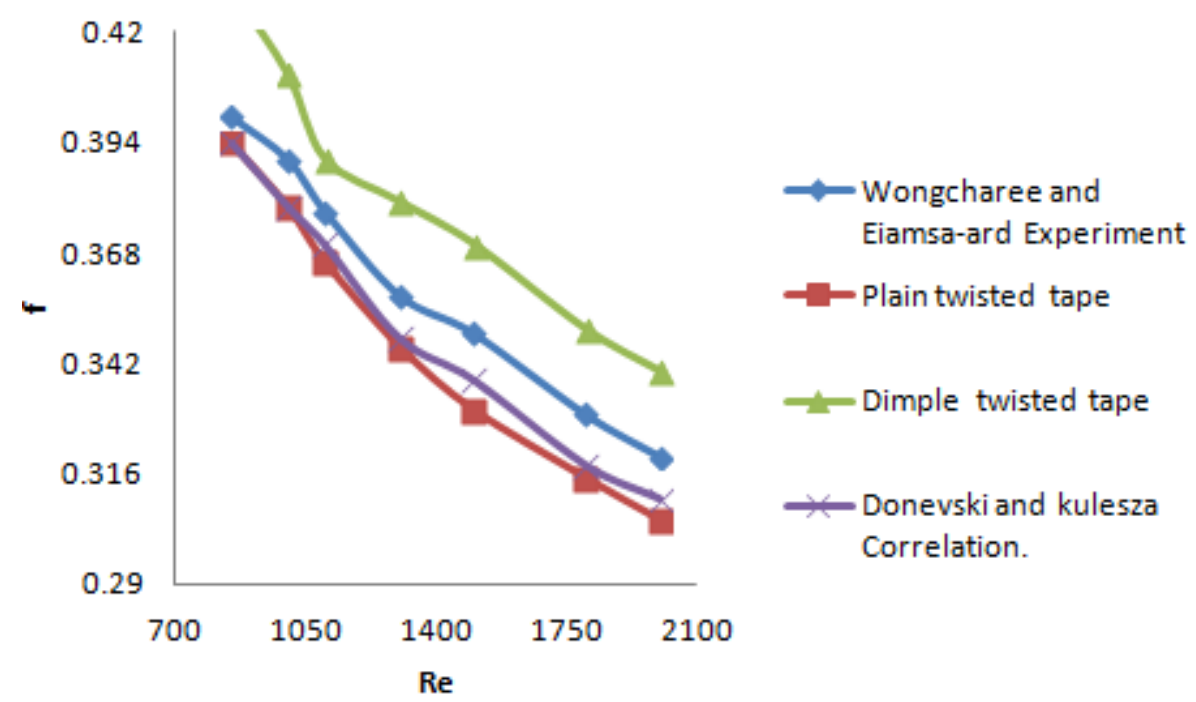

Fig. 8. Validation of friction factor of the PTT and DTT with experimental data and correlation

\subsection{Velocity Contour}

For all the pipe models undertaken, the velocity contour at a randomly chosen axial position is presented in Figure 9 in order to explain the complex flow physics along the duration of domain. Insertion of twisted tape and dimples on twisted tape has been randomly chosen. The velocity profile is almost the same at all locations in the PT (Figure 9(a)) and the highest velocity occurs at the centre, indicating that the flow at these locations is fully formed and parabolic. However, the velocity near the wall at all locations (frame a-f) increases by around 9 percent of that in the PT when the tube is induced with a simple twisted tape (Figure 9(b)). This is due to the vortex that the twisted tape creates. The DTT at position $1 \mathrm{~m}$ (frame f) (Figure 9(c)) raises the swirl and makes the velocity magnitude in the range between 3.8 percent and 2 percent higher than in the upstream regions. 
(A)
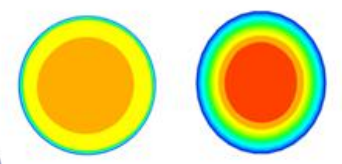

(B)
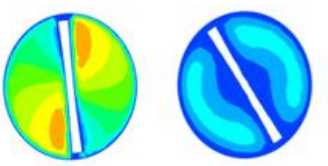

( C)

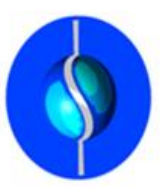

(a)

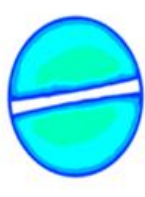

(b)
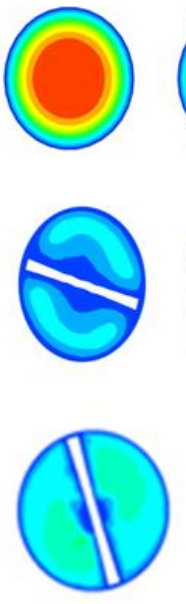

(c)
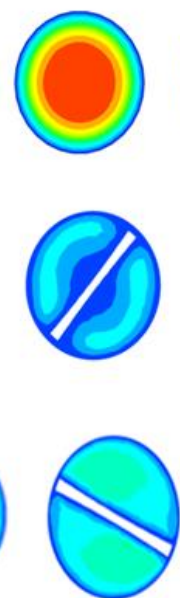

(d)
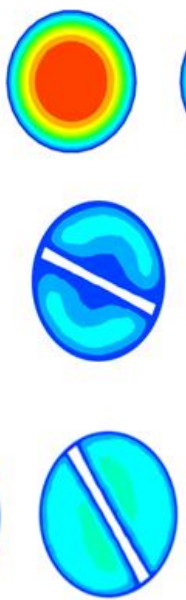

(e)
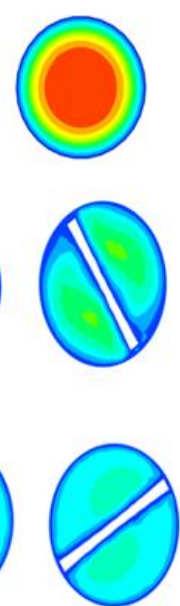

(f)

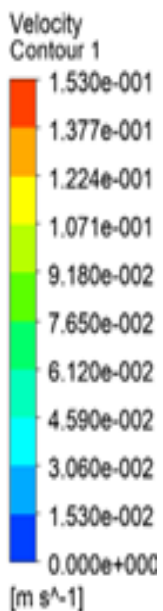

$[\mathrm{m} s-1]$

Fig. 9. Vector plot of velocity for PT (A), TPT (B) and DTTT(C) for $\operatorname{Re}=1800$ at axial location (a) 0 (b) $0.20 \mathrm{~m}$, (c) $0.4 \mathrm{~m}$, (d) $0.60 \mathrm{~m}$, (e) $0.80 \mathrm{~m}$, (f) $1.0 \mathrm{~m}$

\subsection{Temperature Contours}

The temperature contours for plain, twisted tape and dimple twisted tape tube at different locations as shown in Figure 10. In Figure 10(b), the temperature contours at different locations for twisted tape tube is $4.16 \%$ higher than that of plain tube. Because of insert of strips causes flow disturbance which gives rise to augmentation of energy transfer. Due to presence of dimples on strips a small amount of surface area will increase and also disturbance to the flow field hence at axial location of $1 \mathrm{~m}$ (Figure 10(c)) (frame f) the temperature is found to be $1.0 \%$ to $4.0 \%$ higher than upstream axial locations.

The differences in the temperature at various places in the domains are addressed in this segment by documenting the findings in the form of contours. The temperature contours of the different domains at their different positions are shown in Figure 10. The temperature contours are nearly the same for the PT at these positions (Figure 10(a)). The growth of the flow at these stages, resulting in the same thermal boundary layer, may be responsible for this phenomenon. The temperature in the PTT is 4 to 5 percent greater than that in the PT in Figure 10(b), and this rise in temperature is due to the presence of simple twisted tape inserts, resulting in increased disruption of the boundary layer as a consequence of increased fluid mixing.

An extra merging happens in the fluid flow due to the existence of dimples on twisted tape (Figure 10(c)), which again adds more disruption to the flow area. As a consequence, the DTT shows a higher temperature. 
(A)

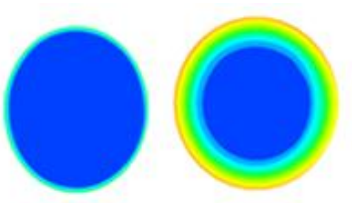

(B)

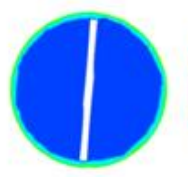

(C)

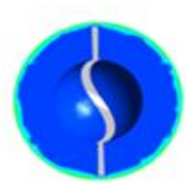

a)
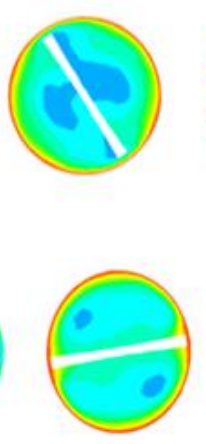

(b)
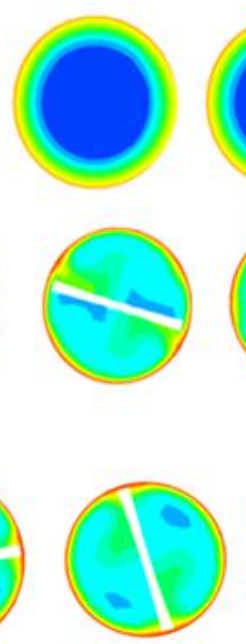

(c)
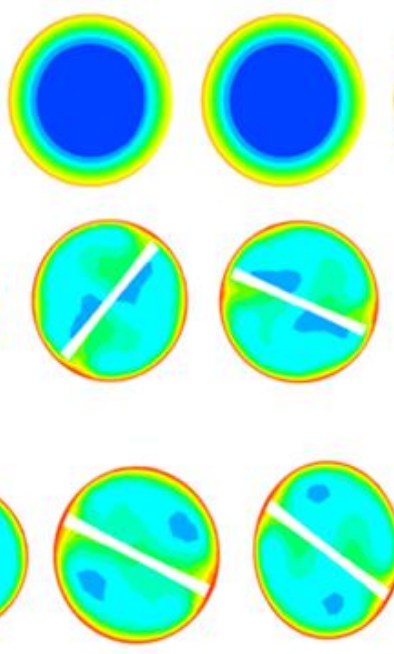

(d)
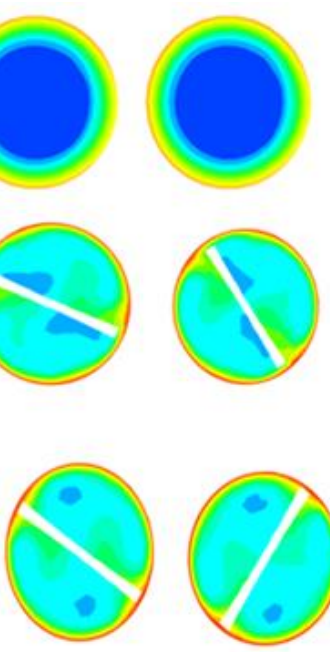

(e)

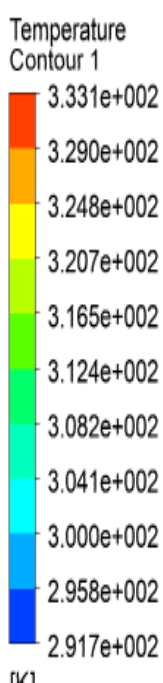

(f)

$[\mathrm{K}]$

Fig. 10. Temperature contour plots PT (A), PTT (B) and DTT(C) tube for $\operatorname{Re}=1800$ at axial location (a) 0 (b) $0.20 \mathrm{~m}$, (c) $0.4 \mathrm{~m}$, (d) $0.60 \mathrm{~m}$, (e) $0.80 \mathrm{~m}$, (f) $1.0 \mathrm{~m}$

\subsection{Thermal Performance Factor}

It is observed that thermal performance of induced tube that is PTT and DTT are above unity. It compares thermal performance of plain tube and induced tube with same pumping power and is mathematically given by

$\eta=N u / N u_{p}\left(f / f_{p}\right)^{-1 / 3}$,

where $\mathrm{Nu}$ and $\mathrm{Nup}$ are Nusselt number of induced tube and plain tube. The thermal performance factor increases as Reynolds number increases giving rise to considerable intensification of heat transfer due to twisted tape and dimples provided on twisted tape. Hence an augmentation of heat transfer proved since thermal factor of induced tube are all above unity. Thermal performance factor of PTT is lower than DTT because of Nusselt number of PTT is lower than DTT tube insert. Figure 11 shows effect of DTT on thermal performance factor with Reynolds number.

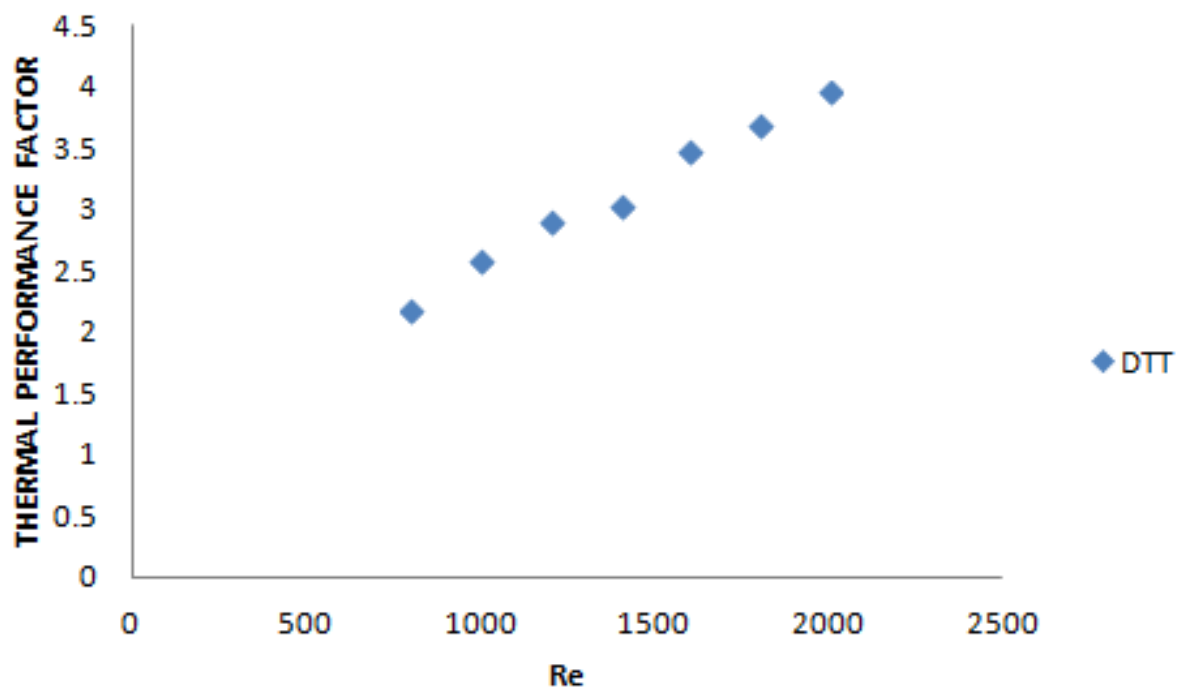

Fig. 11. Effect of DTT on thermal performance factor 


\subsection{Flow Field}

The nature of fluid flow at a location of $0.8 \mathrm{~m}$ is considered. This is achieved to track the direction taken by the fluid particles by drawing streamlines in the flow. Figure 11 displays the pattern of streamlines at an axial position of $0.8 \mathrm{~m}$. With the addition of plain twisted tape and dimples on twisted tape, there is a uniform distribution of streamlines than that of plain tube because of swirls created due to inserts. However, additional disruptions and mixing resulting in collision of fluid and flow separation are generated in DTT Figure 12. Figure 13 and Figure 14 indicates velocity plane and temperature plane for dimple twisted tape at $\operatorname{Re}=1800$.
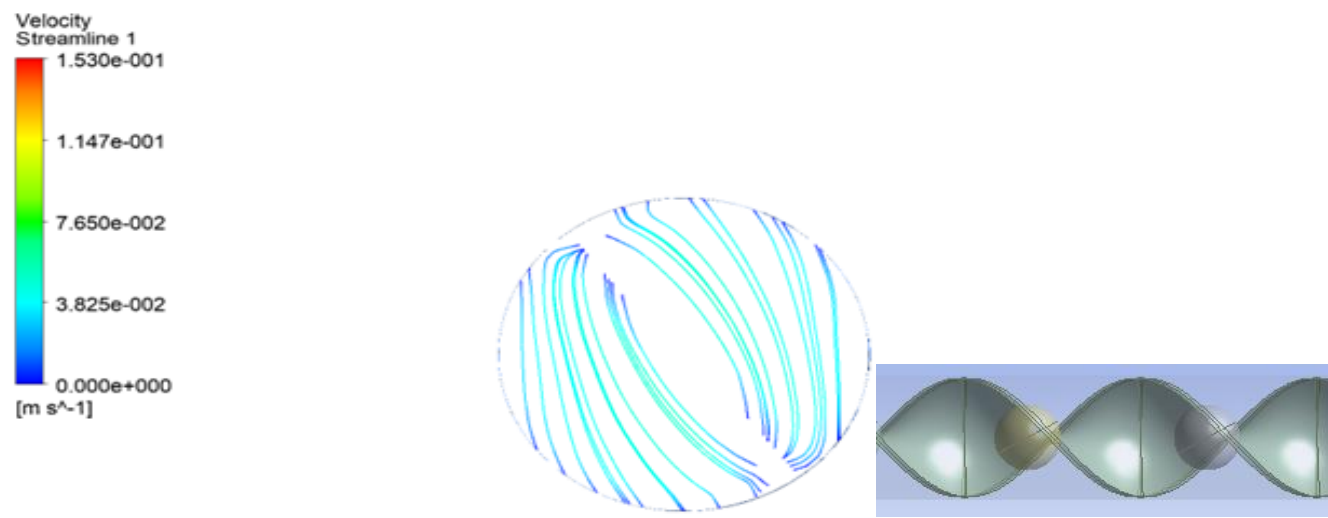

Fig. 12. Streamlines across the domain DTT at axial location of $0.8 \mathrm{~m}$ for $\mathrm{Re}=1800$

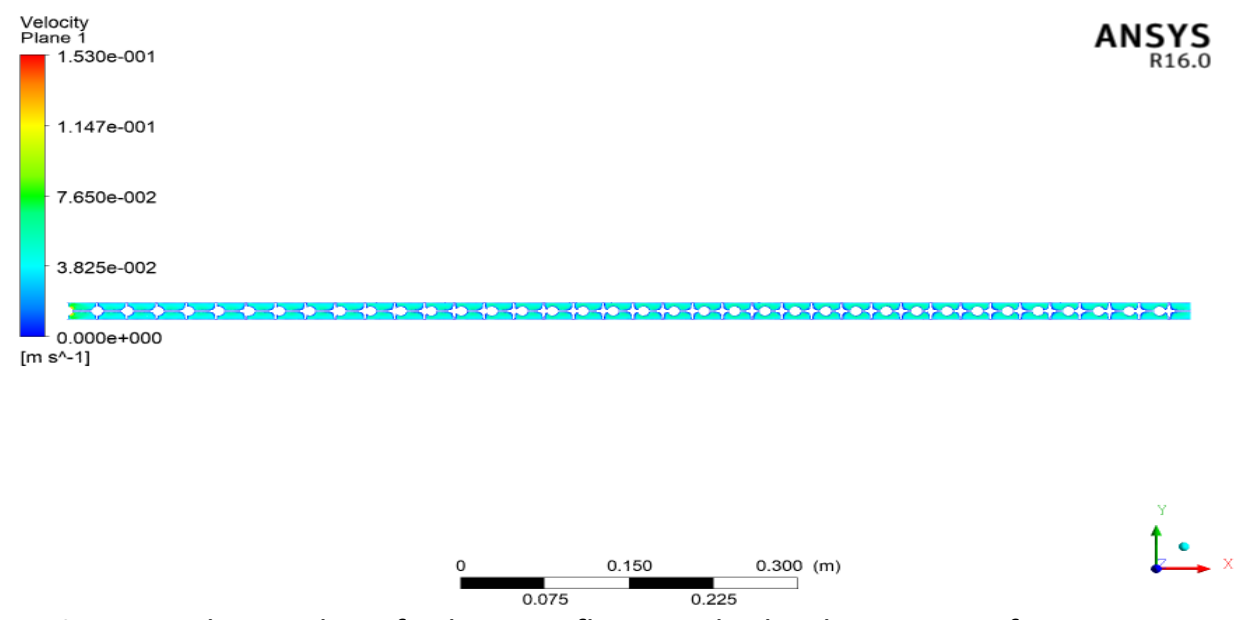

Fig. 13. Velocity plane for laminar flow inside the domain DTT for $\operatorname{Re}=1800$ 


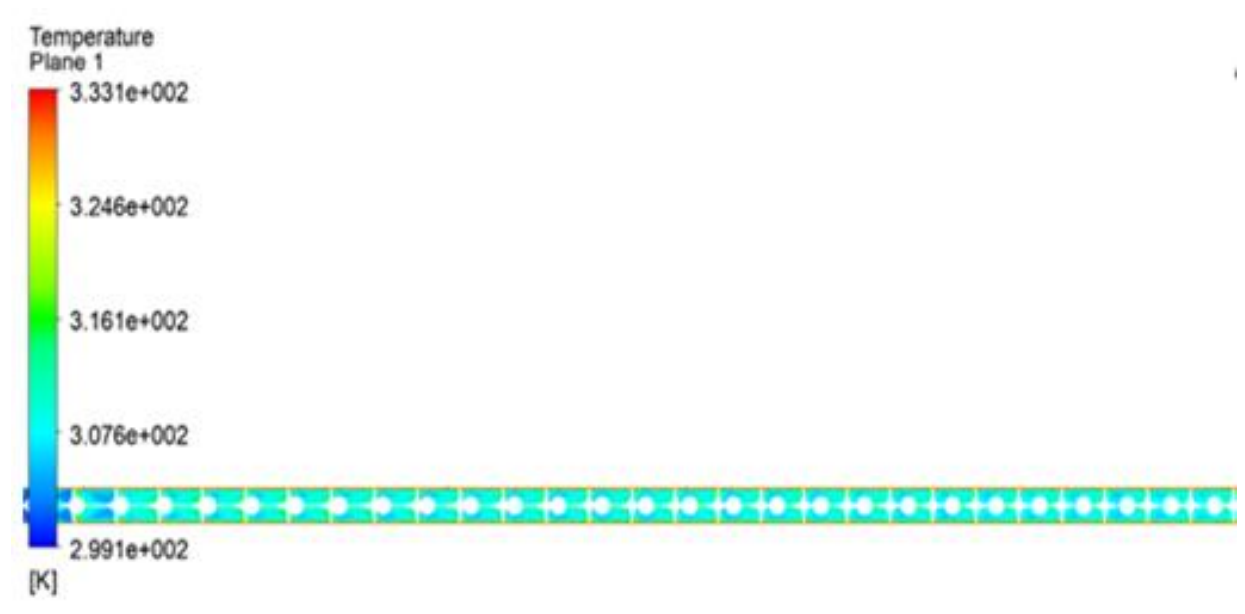

Fig. 14. Temperature plane for laminar flow inside the domain DTT for $\operatorname{Re}=$ 1800

Following highlights can be drawn from above numerical analysis, the velocity contour, temperature contour, local streamlines, velocity vectors and $\mathrm{Nu}$ were presented to illustrate the heat transfer enhancement mechanisms. The variation of $\mathrm{Nu}$ with Re for PTT and DTT tube is compared with experimental data and found that maximum $\mathrm{Nu}$ and friction factor $(\mathrm{f})$ is obtained for DTT tube. The validation of the numerical result of PTT and DTT with the Wongcharee and Eiamsa-ard experiment and Hong and Bergles correlation obtained. Due to presence of dimples there will more disruption of flow area which results in higher temperature. There is an increase of thermal performance factor due to insert of dimple twisted strip gives rise to a considerable intensification of heat transfer. From this investigation we have found that by providing dimples on strip will increase mixing of flow, attachment and interrupt the boundary layer and enhance the heat transfer. The main variable found was thermal performance factor which was above unity hence an intensification of heat transfer achieved. By varying the pitch of strip and also varying the pitch of dimple how exactly the flow field will behave with respect to Reynolds number can be proposed for further work.

\section{Conclusion}

The following conclusion can be drawn by present analysis.

i. $\quad$ The DTT tube presents better heat transfer intensification than PTT and PT.

ii. The rate of heat transfer is always higher for full length TT pipe with dimples than that of PTT

iii. The simulation results of Nusselt number versus Re number of the PT with the experimental data gives a variation of $2.5 \%$

iv. The simulation results of Nusselt number versus Re number of the PTT tube with the experimental data gives a variation of $5.75 \%$.

v. The simulation results of Nusselt number versus Re number of the DTT tube with the experimental data gives a variation of $9.5 \%$.

vi. An intensification of heat transfer achieved since thermal performance factor of DTT is above unity 


\section{References}

[1] Guo, Jian, Aiwu Fan, Xiaoyu Zhang, and Wei Liu. "A numerical study on heat transfer and friction factor characteristics of laminar flow in a circular tube fitted with center-cleared twisted tape." International Journal of Thermal Sciences 50, no. 7 (2011): 1263-1270. https://doi.org/10.1016/j.ijthermalsci.2011.02.010

[2] Wongcharee, K., and S. Eiamsa-ard. "Friction and heat transfer characteristics of laminar swirl flow through the round tubes inserted with alternate clockwise and counter-clockwise twisted-tapes." International Communications in Heat and Mass Transfer 38, no. 3 (2011): 348-352. https://doi.org/10.1016/i.icheatmasstransfer.2010.12.007

[3] Eleiwi, Muhammad Asmail, Tashkent Ahmad Tahseen, and Ayad Fouad Hameed. "Numerical study of fluid flow and heat transfer in a backward facing step with three adiabatic circular cylinder." Journal of Advanced Research in Fluid Mechanics and Thermal Sciences 72, no. 1 (2020): 80-93. https://doi.org/10.37934/arfmts.72.1.8093

[4] Yang, Kuanli, and Wei Liu. "Forming an equivalent thermal boundary layer for fully-developed laminar tube flow and its field energy analysis" Journal of Engineering Thermo-physics 28, no. 2 (2007): 283-285.

[5] Liu, Wei, and Kun Yang. "Mechanism and numerical analysis of heat transfer enhancement in the core flow along a tube." Science in China Series E: Technological Sciences 51, no. 8 (2008): 1195-1202. https://doi.org/10.1007/s11431-008-0167-9

[6] Eiamsa-Ard, Smith, Chinaruk Thianpong, Petpices Eiamsa-Ard, and Pongjet Promvonge. "Convective heat transfer in a circular tube with short-length twisted tape insert." International Communications in Heat and Mass Transfer 36, no. 4 (2009): 365-371. https://doi.org/10.1016/j.icheatmasstransfer.2009.01.006

[7] Promvonge, Pongjet, and Smith Eiamsa-Ard. "Heat transfer behaviors in a tube with combined conical-ring and twisted-tape insert." International Communications in Heat and Mass Transfer 34, no. 7 (2007): 849-859. https://doi.org/10.1016/j.icheatmasstransfer.2007.03.019

[8] Piya, Ibroheng, Pathomporn Narato, Makatar Wae-hayee, and Chayut Nuntadusit. "Flow and Heat Transfer Characteristic of Inclined Oval Trench Dimples with Numerical Simulation." CFD Letters 12, no. 11 (2020): 61-71. https://doi.org/10.37934/cfdl.12.11.6171

[9] Sarviya, R. M., and Veeresh Fuskele. "Heat transfer and pressure drop in a circular tube fitted with twisted tape insert having continuous cut edges." Journal of Energy Storage 19 (2018): 10-14. https://doi.org/10.1016/i.est.2018.07.001

[10] Kumar, Anil, R. P. Saini, and J. S. Saini. "Experimental investigation on heat transfer and fluid flow characteristics of air flow in a rectangular duct with Multi v-shaped rib with gap roughness on the heated plate." Solar Energy 86, no. 6 (2012): 1733-1749. https://doi.org/10.1016/i.solener.2012.03.014

[11] Kongkaitpaiboon, V., K. Nanan, and S. Eiamsa-Ard. "Experimental investigation of heat transfer and turbulent flow friction in a tube fitted with perforated conical-rings." International Communications in Heat and Mass Transfer 37, no. 5 (2010): 560-567. https://doi.org/10.1016/i.icheatmasstransfer.2009.12.015

[12] Khoshvaght-Aliabadi, Morteza, and Zahra Arani-Lahtari. "Forced convection in twisted minichannel (TMC) with different cross section shapes: a numerical study." Applied Thermal Engineering 93 (2016): 101-112. https://doi.org/10.1016/i.applthermaleng.2015.09.010

[13] Roy, Sarbendu, and Sujoy Kumar Saha. "Thermal and friction characteristics of laminar flow through a circular duct having helical screw-tape with oblique teeth insert and wire coil inserts." Experimental Thermal and Fluid Science 68 (2015): 733-743. https://doi.org/10.1016/j.expthermflusci.2015.07.007

[14] Arulprakasajothi, M., K. Elangovan, K. Hema Chandra Reddy, and S. Suresh. "Experimental investigation on heat transfer effect of conical strip inserts in a circular tube under laminar flow." Frontiers in Energy 10, no. 2 (2016): 136-142. https://doi.org/10.1007/s11708-015-0389-z

[15] Eiamsa-Ard, Smith, Panida Seemawute, and Khwanchit Wongcharee. "Influences of peripherally-cut twisted tape insert on heat transfer and thermal performance characteristics in laminar and turbulent tube flows." Experimental Thermal and Fluid Science 34, no. 6 (2010): 711-719. https://doi.org/10.1016/i.expthermflusci.2009.12.013

[16] Lin, Zhi-Min, Liang-Bi Wang, Mei Lin, Wei Dang, and Yong-Heng Zhang. "Numerical study of the laminar flow and heat transfer characteristics in a tube inserting a twisted tape having parallelogram winglet vortex generators." Applied Thermal Engineering 115 (2017): 644-658. https://doi.org/10.1016/i.applthermaleng.2016.12.142

[17] Feng, Zhenfei, Xiaoping Luo, Feng Guo, Haiyan Li, and Jinxin Zhang. "Numerical investigation on laminar flow and heat transfer in rectangular micro channel heat sink with wire coil inserts." Applied Thermal Engineering 116 (2017): 597-609. https://doi.org/10.1016/i.applthermaleng.2017.01.091

[18] Bhadouriya, Rambir, Amit Agrawal, and S. V. Prabhu. "Experimental and numerical study of fluid flow and heat transfer in a twisted square duct." International Journal of Heat and Mass Transfer 82 (2015): 143-158. https://doi.org/10.1016/i.ijheatmasstransfer.2014.11.054 
[19] Rahimi-Esbo, Mazaher, Yousef Vazifeshenas, Alireza Khalili Asboei, Reza Mohammadyari, and Vandana. "Numerical simulation of twisted tapes fitted in circular tube consisting of alternate axes and regularly spaced tapes." Acta Scientiarum. Technology 40 (2018): e37348. https://doi.org/10.4025/actascitechnol.v40i1.37348

[20] Ranjan, Hrishiraj, Anand Kumar Bharti, Madhu Sruthi Emani, Josua Petrus Meyer, and Sujoy Kumar Saha. "New combined heat transfer enhancement techniques used in laminar flow through non-circular ducts." Applied Thermal Engineering 163 (2019): 114325. https://doi.org/10.1016/i.applthermaleng.2019.114325

[21] Abdullah, Ahmed L., and Fuat Yilmaz. "Computational analysis of heat transfer enhancement in a circular tube fitted with different inserts." Journal of Advanced Research in Fluid Mechanics and Thermal Sciences 40, no. 1 (2017): 59-69. 